\title{
Green Computing: An Era of Energy Saving Computing of Cloud Resources
}

\author{
Shailesh Saxena \\ Research Scholar, MJP Rohilkhand University, Bareilly, India \\ Email: shaileshgla@gmail.com
}

\author{
Mohammad Zubair Khan \\ Department of CS, College of Computer Science and Engg., Taibah University, Medina, KSA \\ Email: mkhanb@taibahu.edu.sa
}

\author{
Ravendra Singh \\ Department of CS and IT, MJP Rohilkhand University, Bareilly, India \\ Email: rsiet2002@gmail.com
}

Received: 02 March 2021; Accepted: 28 April 2021; Published: 08 June 2021

\begin{abstract}
Cloud computing is a widely acceptable computing environment, and its services are also widely available. But the consumption of energy is one of the major issues of cloud computing as a green computing. Because many electronic resources like processing devices, storage devices in both client and server site and network computing devices like switches, routers are the main elements of energy consumption in cloud and during computation power are also required to cool the IT load in cloud computing. So due to the high consumption, cloud resources define the high energy cost during the service activities of cloud computing and contribute more carbon emissions to the atmosphere. These two issues inspired the cloud companies to develop such renewable cloud sustainability regulations to control the energy cost and the rate of $\mathrm{CO}_{2}$ emission. The main purpose of this paper is to develop a green computing environment through saving the energy of cloud resources using the specific approach of identifying the requirement of computing resources during the computation of cloud services. Only required computing resources remain ON (working state), and the rest become OFF (sleep/hibernate state) to reduce the energy uses in the cloud data centers. This approach will be more efficient than other available approaches based on cloud service scheduling or migration and virtualization of services in the cloud network. It reduces the cloud data center's energy usages by applying a power management scheme (ON/OFF) on computing resources. The proposed approach helps to convert the cloud computing in green computing through identifying an appropriate number of cloud computing resources like processing nodes, servers, disks and switches/routers during any service computation on cloud to handle the energy-saving or environmental impact.
\end{abstract}

Index Terms: Computation Resource; Cloud Services; Green Computing; Energy Consumption; Sleep-Mode.

\section{Introduction}

Cloud computing is a common computing environment that provides a variety of on-demand technologies and services. Cloud Computing offers cloud users with hardware, applications, and apps. Cloud computing incorporates computing resources such as equipment, applications and networking that can be transmitted over the Web as a service [1]. Systems such as Open Models for cloud delivery distribute vast resources and services in cloud infrastructure for customers. To create a private network, a private model is used. It's only within the context of a company. The Group model is used to distribute cloud user's network tools. Hybrid architecture is a combination of two or more cloud activities with internal and external resource management [2].

At the same period as on-demand demand for software storage business often raises the largest growth in Internet usage, the cloud computing service on-demand is raised. The cloud service company constructs a large cloud data center which has high resource availability, providing a high power cost for cloud computing, thus requiring high energy consumption [3]. Power can be reduced by reducing the amount of energy that meets the demands for workload; thus, redundant resources are shut down or put in low power mode while the workload is smaller. Likewise, when the workload rises, additional resources are moved to high electricity [4].

Although we may be mindful of the use of the cloud computing tools, there are many challenges and incredible energy consumption, production of carbon dioxide and related price problems. As a result, cloud service providers are 
becoming extremely damaged for the operation and maintenance of cloud resources [5]. Data clients use all the outlets provided by data operators. Nonetheless, software computing services tend to consume electrical power within the range of many Megawatts [6].

Recent developments in processing usable resource technologies have rendered energy consumption more difficult to reach the actual level. Nevertheless, because the amount of energy concerned with the assistance of electronic sources is first and foremost influenced by their mode of use, it remains a critical challenge for technological tools. In many words, a larger amount of energy use is measured by efficient use of resources for use of useful resources. In addition to scripting, virtualization and reduction, it includes a variety of power-saving techniques [7].

The computing services are the foundation of the cloud. The use of capital at all levels is not restricted to the increase in computing and data market. Assets are exchanged with multiple customers to provide dynamism allocated and reassigned to the multi-tenant model, which has distinct organizational and technological assets in accordance with the consumer call [8].

Cloud requires thousands of energy to provide the services to the customer and to run various categories, consuming massive power, and in recent years it has been cold. Different hardware innovations, such as virtualization, containers and computational development, are possible, such as machine efficient algorithms to reduce energy consumption [9]. Through maximizing the elimination of energy consumption and increasing the efficiency of cooling and electrical power in the Cloud data center infrastructure you are able to achieve the intensity green cloud. According [10] the cloud resources consumed near about 1.1\%-1.5\% of the world's energy in the last few years. It is also expected that after completion of the year 2020 the total energy consumption of cloud resources will be more than $140 \mathrm{TH}$.

Green cloud computing is designed to reduce energy usage not just by allowing the economic operation and use of computing resources. The most important objective of novice cloud computing is the control of energy-conscious data, economic policies and algorithms for virtualization, resource claim, allocation of resources, employment and activities in the field, as well as many land and environmentally friendly conventional technologies[11] for the next millennium. The transfer of services is a useful way for handling cloud resources in particular in the short and long-term use of cloud resources. The efficient green use of cloud assets to reduce the number of active cloud resources and to put unused resources directly into the power saving mode or perhaps to switch off some idle resources [12].

\section{Related Review}

The distribution of resources is one of the challenges in the cloud environment, since the user may access services at any moment from anywhere. The key challenge in a cloud is for users who have dynamic requests for resources to allocate resources in support of their application patterns. The unstable and complex requests will operate on cloud services throughout the network. The software is incredibly important, because the program correlated with central processor, memory, storage and database calculation is generally called the IT tool at intervals in cloud environments [14]. The problem of allocation of resources is rather costly and calls for expectations and a variety of system management configuration processes for job servers, a collection of service level arrangement for consolidating activities and a decrease in the loss of electricity and expense of use of services. The difficulty of resource allotment entails the appropriate allocation and economic use of available resources for the use of the square resource allotment measure in order to boot strictly due to workloads which lead to completely extraordinary demands for resources on behalf of cloud providers [15].

In this regard the energy efficient approach in cloud computing is more essential to handle the energy saving issue or environmental impact. Table 1 describes the review of some approaches related to energy efficient computing in cloud.

Table 1. Review of Energy Efficient Computing Approaches in Cloud

\begin{tabular}{|c|l|l|l|}
\hline Ref. No & Year \& Publication & \multicolumn{1}{|c|}{ Key Idea } & \multicolumn{1}{c|}{ Findings } \\
\hline 16 & $\begin{array}{l}\text { 2013, } \\
\text { IEEE Transactions on } \\
\text { Cloud Computing vol. } \\
\text { 1(Issue 2), Pg. 215- } \\
228 .\end{array}$ & $\begin{array}{l}\text { VM } \\
\text { Consolidation } \\
\text { based on } \\
\text { sleep mode of } \\
\text { PMs. }\end{array}$ & $\begin{array}{l}\text { In a selection of physical devices is define the limited allocation of resources and } \\
\text { avoid the wasting of energy through transferred them into the sleep mode until a } \\
\text { VM assigned to them. Using the smallest number of PMs Fitting enough to operate a variety } \\
\text { of VMs in a highly dynamic environment, while no prior VMs usage data are operating } \\
\text { throughout the network, despite violation of SLA and reduction of efficiency. In it two } \\
\text { different algorithms are working in such manner that each VM should be paired with } \\
\text { only one request and the victim ship field will share among the allocation of requests. }\end{array}$ \\
\hline 17 & $\begin{array}{l}\text { 2016, } \\
\text { Cluster Computing, } \\
\text { vol. 19 (Issue 2), Pg. } \\
679-698 .\end{array}$ & $\begin{array}{l}\text { Task } \\
\text { SoI:10.1007/s10586- } \\
\text { based on } \\
\text { minimum } \\
\text { number of } \\
\text { migrations. }\end{array}$ & $\begin{array}{l}\text { For routing all queries to the Information Center over the smallest number of PMs, } \\
\text { the resource allocation algorithm system is gone. In the case of any VM release, the } \\
\text { application consolidation algorithms are then dead to insure that machine resources } \\
\text { are used constantly in a cost efficient manner. At the same time, the minimization of } \\
\text { the number of migrations is another major objective, while migration takes time and has } \\
\text { the importance, diagrammatic in the completion times of work that affects the system } \\
\text { performance. }\end{array}$ \\
\hline
\end{tabular}




\begin{tabular}{|c|c|c|c|}
\hline 18 & $\begin{array}{l}2016, \\
\text { Computing, vol. } 98 \\
\text { (Issue 7), Pg. } 751- \\
774 . \\
\text { DOI: } \\
\text { 10.1007/s00607- } \\
014-0407-8\end{array}$ & $\begin{array}{l}\text { Resource } \\
\text { Allocation } \\
\text { based on } \\
\text { Power } \\
\text { Management } \\
\text { through disk } \\
\text { back Up. }\end{array}$ & $\begin{array}{l}\text { Cloud information center power consumption, large-scale, company, disk-based } \\
\text { backup storage. Power management of the storage devices mainly focuses on the } \\
\text { regulation of disk power. Actually, backups and depositors are worthy of being } \\
\text { used as storage devices. The number of disks will enhance the function of the disk } \\
\text { region where the main power shoppers are situated. The separate drives are not used } \\
\text { for power-up yet. Deposit systems are used to position, clean, and recover details } \\
\text { that change multiple drives within the system. }\end{array}$ \\
\hline 19 & $\begin{array}{l}2015, \\
\text { International Journal of } \\
\text { Applied Engineering } \\
\text { Research (2015), vol. } \\
10 \text { (Issue 5), Pg. 0973- } \\
4562 \text {. }\end{array}$ & $\begin{array}{l}\text { VM } \\
\text { assignment } \\
\text { under traffic } \\
\text { condition in } \\
\text { cloud } \\
\text { infrastructure. }\end{array}$ & $\begin{array}{l}\text { The cloud network infrastructure met the network connections, which could be } \\
\text { additionally disrupted and applied to complex programs within the network due to } \\
\text { the increasing functionality and knowledge needs of product apps. Today, a move } \\
\text { towards cloud computing contributes to increased network traffic and congestion. } \\
\text { Congestion may not necessarily be foreseen in a very cloud infrastructure in several } \\
\text { cases. }\end{array}$ \\
\hline 20 & $\begin{array}{l}2012, \\
\text { IEEE Communications } \\
\text { Surveys and Tutorials, } \\
\text { vol. } 14 \text { (Issue 1), Pg. 3- } \\
20 .\end{array}$ & $\begin{array}{l}\text { Virtualization } \\
\text { of application } \\
\text { and services } \\
\text { in cloud } \\
\text { network. }\end{array}$ & $\begin{array}{l}\text { When network enhancement isn't properly enforced, cloud computing will actually } \\
\text { increase the value of contact. When cloud applications have a cloud-based response } \\
\text { unit, end-to-end network access is vital for preventing apps from temporarily } \\
\text { ordering, corrupting information or forestalling staff at remote locations. Additional } \\
\text { information measurement is required to cover application areas, such as virtualized } \\
\text { server apps and software-as-a-services running within the cloud network. }\end{array}$ \\
\hline 21 & $\begin{array}{l}2015, \\
\text { IEEE Transactions on } \\
\text { Cloud Computing }\end{array}$ & $\begin{array}{l}\text { Request } \\
\text { Allocation } \\
\text { under } \\
\text { overloaded } \\
\text { and under } \\
\text { loaded Cloud } \\
\text { conditions. }\end{array}$ & $\begin{array}{l}\text { In the middle layer of the cloud environment between the cloud servers and thus the } \\
\text { consumer demands that delegate processes for several clouds at peak and under } \\
\text { load conditions. Since the task is carried out by the consumer, such criteria are } \\
\text { defined with every user operation as well as time information, time information } \\
\text { process, time limit, requirements for input-output. The distribution of capital is } \\
\text { carried out consecutively and every system at intervals should be dead. If one } \\
\text { system becomes dead at a similar time, the process migrates from one cloud to } \\
\text { another. }\end{array}$ \\
\hline
\end{tabular}

\section{Green Environment of Cloud Computing}

The energy consumption as well as utilization of cloud resources are closely related to the power wattage function that is seen below:

$$
\begin{gathered}
P_{N}=E_{N} / T \\
E_{N}=P_{N} * T
\end{gathered}
$$

Where $\mathrm{P}_{\mathrm{N}}$ is used to measure the power, $\mathrm{T}$ measured the time amount and $\mathrm{E}_{\mathrm{N}}$ measured the consumed energy. The disparity between energy and power is extremely important, since reducing power usage just takes time to decrease energy consumption [22].

The green cloud ecosystems have built themselves to save energy consumed by cloud services. The cloud services contain various processing node, server nodes, network devices and topology, storage devices and other electrical equipment that take part to calculate the total power consumption and it calculate by the formula of energy given as below:

$$
E_{G C R}=E_{P N}+E_{S N}+E_{N E T}+E_{S D}+E_{O E}
$$

$E_{G C R}$-Energy of green cloud resources, $E_{P N}$-Energy of processing nodes, $E_{S N}$-Energy of server nodes, $E_{N E T}$-Energy of network devices like routers/switches, $E_{S D}$-Energy of storage devices (Disk/Racks) and $E_{O E}$-Energy of other electrical equipment. For the physical resources the total energy will also calculated in the following two terms, first $\mathrm{E}_{\text {STATIC }}$ define the maximum energy consumption of any server in spite of working or idle VMs. And second $\mathrm{E}_{\text {DYNAMIC }}$ define the energy consumption of all working VMs at any instance. Assume $\mathrm{n}$ number of VMs are used at any instance for a cloud service than

$$
\mathrm{TE}_{\mathrm{PR}}=\mathrm{E}_{\mathrm{STATIC}}+\mathrm{E}_{\text {DYNAMIC }}=\mathrm{E}_{\mathrm{STATIC}}+\sum_{\mathrm{i}=1}^{\mathrm{n}} \mathrm{E}_{\mathrm{VM} \mathrm{i}}
$$

Every VM have also different components like CPU, RAM, I/O etc. so $E_{V M i}$ can also be describe as sum of energy consumed by the components of VM as:-

$$
\mathbf{E}_{V M i}=E_{V M i}^{C P U}+E_{V M i}^{R A M}+E_{V M i}^{I / O}
$$

$E_{V M i}^{I / O}$ includes the common energy cost of all those devices that involve in I/O operation such as storage on disk and data transfers on network. 
Cloud services such as execution and storage define its energy consumption in terms of the workload of resources like CPU, disk and network interfaces and it will reduce through the policy of ON and OFF the cloud resources. The cloud network replaces the measuring device with a complex reconfiguration that once activated adjusts the storage operation. The inactive shift to the energy saving mode like sleep and hibernate modes is use to reduces the consumption of energy in cloud [23].

\section{Energy Saving Algorithm}

The energy consumption is one of the biggest problems in the cloud computing world. The algorithm for energy saving saved the energy from the estimation of idle cloud resources at any instance. Energy savings means reducing the energy consumption thus producing a similar result.

The algorithm of energy saving starts with determining the task and the scale of the work, how often the different capabilities of cloud infrastructure services can be used. Each resource has its own workspace. The algorithm of energy savings can resolve very difficult questions such as the allocation of resources within the cloud system. It identifies the unaccredited resource and disabled the route. But if the scale of the input product approaches the existing available option then in the next cycle the unused resource is switched on.

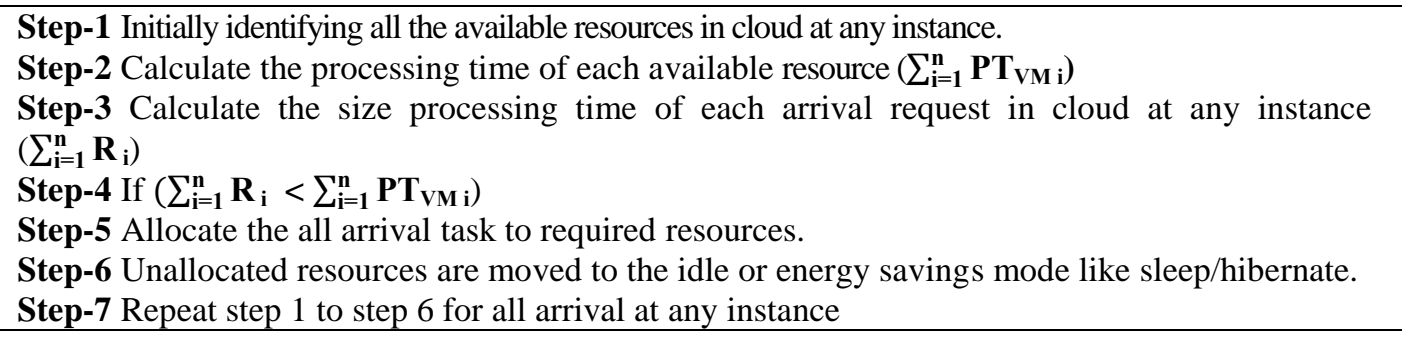

\section{Comparative Analysis}

Energy capacity of cloud resources can estimated in Watts per hour and it is observe that if all cloud resources are in ON stage than consumption of energy during cloud services will be maximum as shown in Table 2.

Table 2. Energy Consumption of Cloud Resources

\begin{tabular}{|c|c|c|c|c|}
\hline \multirow{2}{*}{$\begin{array}{c}\text { Type of } \\
\text { Resource }\end{array}$} & \multirow{2}{*}{$\begin{array}{c}\text { Total } \\
\text { Resources }\end{array}$} & \multicolumn{3}{|c|}{ Energy Consumption (Approximate) } \\
\hline & & Per Hour & Per Day & Per Year \\
\hline $\begin{array}{l}\text { Router / } \\
\text { Switch }\end{array}$ & 30 & $\begin{array}{l}20 * 30=600 \\
\text { Watts }\end{array}$ & $\begin{array}{l}600 * 24=14400 \\
\text { Watts }\end{array}$ & $\begin{array}{l}14400 * 365= \\
5256 \mathrm{KW}\end{array}$ \\
\hline $\begin{array}{l}\text { Processing } \\
\text { Node }\end{array}$ & 50 & $\begin{array}{l}\mathbf{1 0 0} * \mathbf{5 0}= \\
\mathbf{5 0 0 0} \text { Watts }\end{array}$ & $\begin{array}{l}5000 * 24= \\
120000 \text { Watts }\end{array}$ & $\begin{array}{l}120000 * 365= \\
43800 \mathrm{KW}\end{array}$ \\
\hline Server & 10 & $\begin{array}{l}850 * 10= \\
8500 \text { Watts }\end{array}$ & $\begin{array}{l}8500 * 24= \\
204000 \text { Watts }\end{array}$ & $\begin{array}{l}204000 * 365= \\
74460 \mathrm{KW}\end{array}$ \\
\hline $\begin{array}{c}\text { Disk Storage } \\
\text { (Rack) }\end{array}$ & 10 & $\begin{array}{l}1200 * 10= \\
12000 \text { Watts }\end{array}$ & $\begin{array}{l}12000 * 24= \\
288000 \text { Watts }\end{array}$ & $\begin{array}{l}288000 * 365= \\
105120 \mathrm{KW}\end{array}$ \\
\hline
\end{tabular}

But the consumption of energy by cloud resources is calculated in green environment i.e. energy saving mode (ON/OFF stage) then it is observed that energy consumption is reduce according to Table 3.

Table 3. Energy Consumption of Cloud Resources under Green Environment

\begin{tabular}{|c|c|c|c|c|c|}
\hline \multirow{2}{*}{$\begin{array}{l}\text { Type of } \\
\text { Resource }\end{array}$} & \multirow{2}{*}{$\begin{array}{c}\text { Total } \\
\text { Resources }\end{array}$} & \multirow{2}{*}{$\begin{array}{c}\text { No. of } \\
\text { Resource } \\
\text { (Switched } \\
\text { ON) }\end{array}$} & $\begin{array}{c}\text { Energy } \\
\text { Consumption } \\
\end{array}$ & Energy Saving & \multirow{2}{*}{$\begin{array}{c}\text { Energy } \\
\text { Saving } \\
\text { Ratio } \\
(\%)\end{array}$} \\
\hline & & & $\begin{array}{l}\text { (ON Resources) } \\
\text { (Per Hour) }\end{array}$ & $\begin{array}{c}\text { (OFF } \\
\text { Resources) } \\
\text { (Per Hour) }\end{array}$ & \\
\hline $\begin{array}{l}\text { Router / } \\
\text { Switch }\end{array}$ & 30 & 15 & $15^{*} 20=300$ Watts & $\begin{array}{c}15^{*} 20=300 \\
\text { Watts }\end{array}$ & 50 \\
\hline $\begin{array}{l}\text { Processing } \\
\text { Node }\end{array}$ & 50 & 35 & $\begin{array}{c}35 * 100=3500 \\
\text { Watts }\end{array}$ & $\begin{array}{c}15^{*} 100=1500 \\
\text { Watts }\end{array}$ & 30 \\
\hline Server & 10 & 6 & $\begin{array}{c}6^{*} 850=5100 \\
\text { Watts }\end{array}$ & $\begin{array}{c}4 * 850=3400 \\
\text { Watts }\end{array}$ & 40 \\
\hline $\begin{array}{l}\text { Disk Storage } \\
\text { (Rack) }\end{array}$ & 10 & 6 & $\begin{array}{c}6^{*} 1200=7200 \\
\text { Watts }\end{array}$ & $\begin{array}{c}4 * 1200=4800 \\
\text { Watts }\end{array}$ & 40 \\
\hline
\end{tabular}


An energy-efficient control of cloud resources in green environment defines the consumption of energy in three modes i.e. working $(\mathrm{ON})$, idle and sleeping (OFF). Where maximum energy saving is achieved in sleep (OFF) mode of non-useable resources at any instance. Energy consumption will also reduce at some certain level if any resource can remain in idle mode if the resource does not function for a short period of time rather than move to sleep mode instantly, when the resource is empty. Now the principal approach to reduce the energy consumption in cloud to map the requests on the minimum number of physical resources and to turn off idle nodes. So the adoption of active set of servers will be reconfigured dynamically by cloud resources. Energy uses will be minimized as converting the unused resources into energy saving mode i.e. working (ON), idle and sleeping (OFF).

Utilization chart of energy (power) consumption of cloud resources for any instance service time under cloud computing and green cloud environment is shown in Figures 1 and 2 respectively.

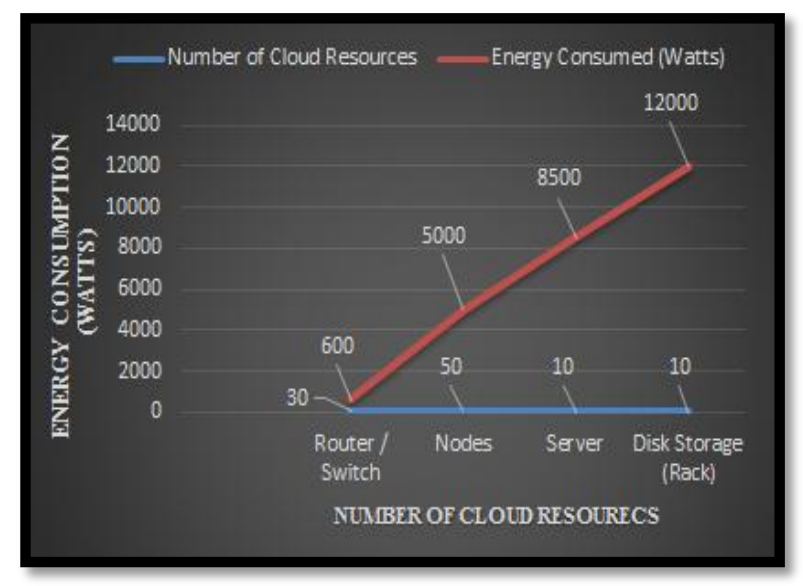

Fig.1. Energy Consumption (per hour) in Cloud Computing (All Resources are ON)

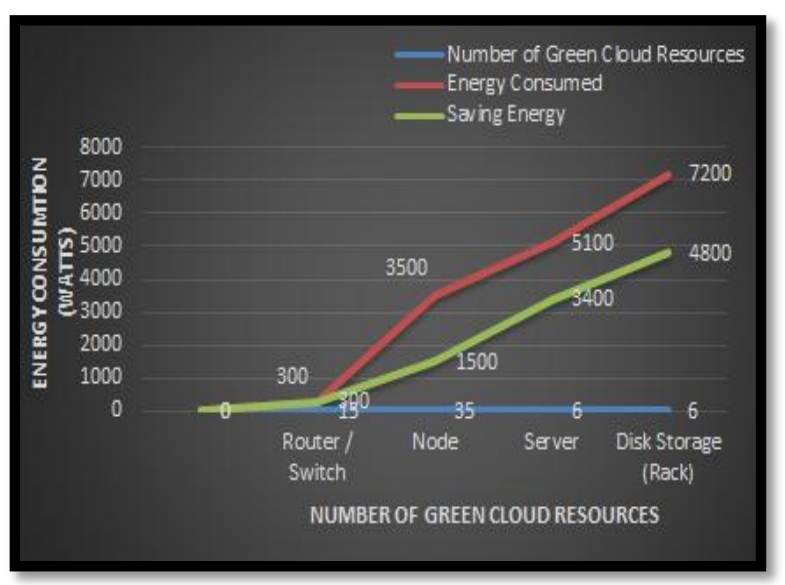

Fig.2. Energy Consumption (per hour) in Green Cloud Computing (Some Resources are OFF)

This indicates that the consumption of energy will effected with a high and low use of resources for computing services in cloud. The index of efficient uses of resources, showing the average usage ratio of all resources for any instance of services. It indicated that, energy consumption will be effective of that resource(s) whose utilization ratio is also effective.

\section{Conclusion and Future Aspect}

In the Green Cloud environment, the most challenging task at present is to turn energy efficiency into energy sustainability. The simulation of energy saving approach shows that the amount of cloud resources are minimized at some certain level as per the requirement of services at any instance and thus the usage of energy will also reduce. The Proposed approach of putting ON only the required resources and rest become OFF regarding the saving of energy during service convert the cloud computing into green computing. Here we have seen that if any resource scheduling allow to OFF near about half cloud resources then we get 40 to 50 percent reduction in the consumption of the energy. So that this reduction of energy usage affected the service cost in cloud computing as the reduction of electricity charges and eco-environment through less omit of $\mathrm{CO}_{2}$. 
In future, if we able to predict the service request in advance then the appropriate number of computing resources that can accommodate predicted amount of service requests can be activated and Cloud systems will save more energy by preventing excessive activation of computing resources. Due to this service prediction approach we will able to define the state (ON/OFF) of the computing resources in advance. So that the energy comsumed in converting the state of computing resources from $\mathrm{ON}$ to $\mathrm{OFF}$ during computation will save.

\section{References}

[1] Buyya, R.,"Introduction to the IEEE Transactions on Cloud Computing”, in IEEE Transactions on Cloud Computing,(2013) $1(1), 3-21$.

[2] Lee, Y. C., and Zomaya, A. Y. , "Energy Efficient Utilization of Resources in Cloud Computing Systems", in The Journal of Supercomputing (2012), Vol. 60(Issue 2), Pg. 268-280. doi: 10.1007/s11227-010-0421-3

[3] Buyya, R., Yeo, C. S., Venugopal, S., Broberg, J., and Brandic, I., "Cloud Computing and Emerging IT Platforms: Vision, Hype, and Reality for Delivering Computing as the 5th Utility", in Future Generation computer systems (2009), vol. 25(Issue 6), Pg. 599-616.

[4] Farahnakian, F., Ashraf, A., Pahikkala, T., Liljeberg, P., Plosila, J., Porres, I., and Tenhunen, H. , "Using Ant Colony System to Consolidate VMs for Green Cloud Computing”, in IEEE Transactions on Services Computing (2015), vol. 8(Issue 2), Pg. 187198.

[5] Buyya, R., Beloglazov, A., and Abawajy, J., "Energy-Efficient Management of Data Center Resources for Cloud Computing: a Vision, Architectural Elements, and Open Challenges", in 2010 arXiv preprint arXiv:1006.0308. Las vegas.

[6] Boru, D., Kliazovich, D., Granelli, F., Bouvry, P., and Zomaya, A. Y., "Energy-efficient Data Replication in Cloud Computing Datacenters", in Cluster computing (2015), vol. 18 (Issue 1), Pg. 385-402.

[7] Lee, Y. C., and Zomaya, A. Y. , "Energy Efficient Utilization of Resources in Cloud Computing Systems", in The Journal of Supercomputing (2012), vol. 60 (Issue 2), Pg. 268-280.

[8] Ala'a Al-Shaikh, H. K., Sharieh, A., and Sleit, A., "Resource Utilization in Cloud Computing as an Optimization Problem", in Resource (2016), vol. 7(Issue 6).

[9] Shaikh, F. K., Zeadally, S., and Exposito, E., "Enabling Technologies for Green Internet of Things", in IEEE Systems Journal (2017), vol. 11(Issue 2), Pg. 983-994.

[10] The Environmental Protection Agency (EPA) estimated one kilowatt- hour produces 1.52 pounds of carbon dioxide (excluding line-losses)

[11] Beloglazov, A., Abawajy, J., and Buyya, R. , "Energy-Aware Resource Allocation Heuristics for Efficient Management of Data Centers for Cloud Computing", in Future generation computer systems (2012), vol. 28 (Issue 5), Pg. 755-768.

[12] Lee, Y. C., and Zomaya, A. Y. , "Energy Efficient Utilization of Resources in Cloud Computing Systems", in The Journal of Supercomputing (2012), vol. 60 (Issue 2), Pg. 268-280.

[13] Boru, D., Kliazovich, D., Granelli, F., Bouvry, P., and Zomaya, A. Y. , "Energy-Efficient Data Replication in CloudComputing Data- centers", in Cluster computing (2015), vol. 18 (Issue 1), Pg. 385-402. doi:10.1007/s10586-014- 0404-x

[14] Hsu, C. H., Slagter, K. D., Chen, S. C., and Chung, Y. C., "Optimizing Energy Consumption with Task Consolidation in Clouds", in Information Sciences(2014), vol. 25 (Issue 8), Pg. 452-462.

[15] Cao, Z., Lin, J., Wan, C., Song, Y., Zhang, Y., and Wang, X., "Optimal Cloud Computing Resource Allocation for Demand Side Man-agreement in Smart Grid”, in IEEE Transactions on Smart Grid (2017), vol. 8 (Issue 4), Pg. 1943-1955.

[16] Mastroianni, C., Meo, M., and Papuzzo, G. , "Probabilistic Consolidation of Virtual Machines in Self-Organizing Cloud Data Centers", in IEEE Transactions on Cloud Computing (2013), vol. 1(Issue 2), Pg. 215-228.

[17] Kaur, T., and Chana, I. , "Energy Aware Scheduling of Deadline- Constrained Tasks in Cloud Computing", in Cluster Computing (2016), vol. 19 (Issue 2), Pg. 679-698. doi: 10.1007/s10586-016-0566-9

[18] Hameed, A., Khoshkbarforoushha, A., Ranjan, R., Jayaraman, P. P., Kolodziej, J., Balaji, P., and Khan, S. U., “A Survey and Taxonomy On Energy Efficient Resource Allocation Techniques for Cloud Computing Systems", in Computing (2016), vol. 98 (Issue 7), Pg. 751-774. doi: 10.1007/s00607- 014-0407-8

[19] Josphin, J., Suprakash, S., and Balakannan, S. P. , “An Optimal Virtual Machine Assignment Using Firefly Algorithm For Achieving Energy Efficiency In Data Center", in International Journal of Applied Engineering Research (2015), vol. 10 (Issue 5), Pg. 0973-4562.

[20] Bianzino, A. P., Chaudet, C., Rossi, D., and Rougier, J. L., "A Survey of Green Networking Research", in IEEE Communications Surveys and Tutorials (2012), vol. 14 (Issue 1), Pg. 3-20.

[21] Fiandrino C., Kliazovich D., Bouvry P., and Zomaya A. , "Performance and Energy Efficiency Metrics for Communication Systems of Cloud Computing Data Centers", in IEEE Transactions on Cloud Computing (2015).

[22] Sofia A. S., and Kumar P. G. ,"Implementation of Energy Efficient Green Computing in Cloud Computing", in International Journal of Enterprise Network Management (2015), vol. 6 (Issue 3), Pg. 222-237.

[23] Gu C., Huang H., and Jia X. , "Power Metering for Virtual Machine in Cloud Computing-Challenges and Opportunities", in IEEE Access (2014), vol. 2, Pg. 1106-1116.

[24] Liu, X. F., Zhan, Z. H., Deng, J. D., Li, Y., Gu, T., and Zhang, J. ,“An Energy Efficient Ant Colony System for Virtual Machine Placement in Cloud Computing”, in IEEE Transactions on Evolutionary Computation (2018), vol. 22 (Issue 1).

[25] Karuppasamy, M., Suprakash, S., Balakannan, S. P., and Krishnankoil, S. ,"Energy Efficient Cloud Networks Towards A Sustainable Green Environment”, in International Journal of Science and Environment (2013), vol. 7 (Issue 8), Pg: 2320-8791

[26] Wang, W., Liang, B., and Li, B. , "Multi-Resource Fair Allocation in Heterogeneous Cloud Computing Systems", in IEEE Transactions on Parallel and Distributed Systems (2015), vol. 26 (Issue 10), 2822-2835.

[27] Shameer, A. P., Haseeb, V. V., and Mini Mol, V. K., "Green Approach for Reducing Energy Consumption-A Case Study Report" in International Journal (2015), vol. 5, Issue 1. 
[28] Quang-Hung, N., Thoai, N., and Son, N. T. , "Epobf: Energy Efficient Allocation of Virtual Machines in High Performance Computing Cloud" in Journal of Science and Technology, (2013) (4B), Pg: 173-182, arXiv:1310.780151.

[29] Kessaci, Y., Melab, N., and Talbi, E. G. , “ An Energy-Aware Multi- Start Local Search Heuristic for Scheduling VMs on the OpenNebula Cloud Distribution" in the proceeding of International Conference on High Performance Computing and Simulation (HPCS) (2012), Pg. 112-118.

[30] Kaur, T., and Chana, I., "Energy Aware Scheduling of Deadline- Constrained Tasks in Cloud Computing", in Cluster Computing (2016), vol. 19 (Issue 2), Pg. 679-698. doi: 10.1007/s10586 01605669

[31] Sadia Anayat. " A Study of Power Management Techniques in Green Computing ", International Journal of Education and Management Engineering (IJEME), Vol.10, No.3, pp.42-51, 2020.DOI: 10.5815/ijeme.2020.03.05

[32] Gaganpreet Kaur Sehdev, Anil Kumar, "Performance Evaluation of Power Aware VM Consolidation using Live Migration", International Journal of Computer Network and Information Security (IJCNIS), vol.7, no.2, pp. 67-76, 2015. DOI: 10.5815/ijcnis.2015.02.08

\section{Authors' Profiles}

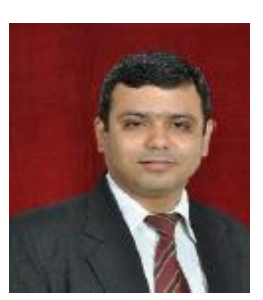

Shailesh Saxena is now pursuing his Ph.D in Computer Science at Faculty of Engineering, M. J. P. Rohilkhand University, Bareilly, India. He received the Master of Technology degree in CSE from U. P. Technical University, Lucknow, India, in 2012. His main area of research is computing. He published several research papers on Distributed Computing, Grid Computing and Cloud Computing. Now he continues his research on Energy-Saving Computing or Green Computing

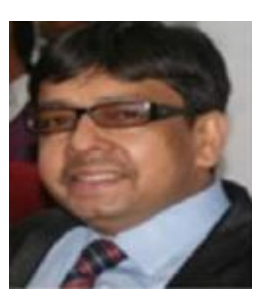

Mohammad Zubair Khan received the Master of Technology degree in CSE from U. P. Technical University, Lucknow, India, in 2006, and the Ph.D. degree in computer science and information technology from Faculty of Engineering, M. J. P. Rohilkhand University, Bareilly, India. He was the Head and an Associate Professor with the Department of CSE, Invertis University, Bareilly, India. He has more than 18 years of teaching and research experience. He is currently an Associate Professor with the Department of Computer Science, College of Computer Science and Engineering, Taibah University. He has published more than 60 journals and conference papers. His current research interests include data mining, big data, IOT, parallel and distributed computing, the theory of computations, and computer networks. He has been a member of the Computer Society of India since 2004.

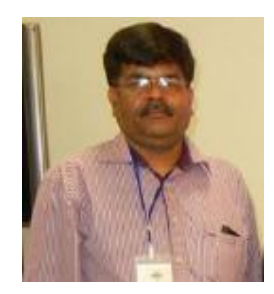

Dr. Ravendra Singh is presently working as a Professor in Department of CS \& IT, Faculty of Engineering, M.J.P. Rohilkhand University, Bareilly, India. He has more than 22 year academic experience including 17 years of research. He has authored over 90 publications and 4 books. In past he did maximum research in the field of parallel and distributed computing or computer network regarding task allocation \& scheduling. Currently his research includes Artificial intelligence, Machine learning, Deep learning and its applications.

How to cite this paper: Shailesh Saxena, Mohammad Zubair Khan, Ravendra Singh," Green Computing: An Era of Energy Saving Computing of Cloud Resources ", International Journal of Mathematical Sciences and Computing(IJMSC), Vol.7, No.2, pp. 42-48, 2021. DOI: $10.5815 /$ ijmsc.2021.02.05 